\title{
Allergies in Dental Practice - Questionnaire-Based Study
}

\author{
Hajnal Lőrincz¹, Henrietta Zsófia Kovács², Bernadette Kerekes-Máthé3 \\ 1 Dental student, Faculty of Dental Medicine, "George Emil Palade” University of Medicine, Pharmacy, Science and Technology, \\ Târgu Mureş, Romania \\ 2 Faculty of Dental Medicine, "George Emil Palade" University of Medicine, Pharmacy, Science and Technology, Târgu Mureş, Romania \\ 3 Department of Morphology of Teeth and Dental Arches, Technology of Dental Prosthesis and Dental Materials, Faculty of Dental \\ Medicine, "George Emil Palade" University of Medicine, Pharmacy, Science and Technology, Târgu Mureş, Romania
}

\section{CORRESPONDENCE}

Henrietta Zsófia Kovács

Str. Gheorghe Marinescu nr. 38

540139 Târgu Mureş, Romania

Tel: +36 703440229

E-mail: k.heni14@yahoo.com

\section{ARTICLE HISTORY}

Received: July 17, 2020

Accepted: September 1, 2020
Hajnal Lőrincz • Str. Gheorghe Marinescu nr. 38 540139 Târgu Mureş, Romania. Tel: +40 265215 551, E-mail: lorincz_hajnal@yahoo.com

Bernadette Kerekes-Máthé • Str. Gheorghe Marinescu nr. 38, 540139 Târgu Mureș, Romania. Tel: +40265 215 551, E-mail: mdetti3@yahoo.com

\section{ABSTRACT}

Background: Allergy is one of the most widespread diseases in this century. Allergy-causing materials used in dentistry are most frequently metals, such as nickel, cobalt, palladium, and amalgam, certain components of dental composites, denture resin materials, and even certain mouthwash components. The aim of this study was to assess dentists' experience regarding allergies occurring in their practice among patients and among dental team members. Material and methods: We conducted a questionnaire-based study, in which 104 dentists responded. Results: Immediate allergic reactions were more often caused by different drugs, detergents, and anesthetics, while delayed allergic reactions were mostly caused by acrylates. Allergic reactions occurred more often among women than men, but the difference was not statistically significant $(p=0.3)$. Conclusions: Our results suggest that allergies in dentistry appear mainly among adults, caused mostly by acrylates, metals, and different drugs. Immediate allergic reactions are often present, and mostly women are susceptible to allergies.

Keywords: allergy, biocompatibility, dental materials

\section{INTRODUCTION}

Allergies were known for centuries, but their prevalence has increased significantly in the last few decades. According to Nékám K., allergies will become much more prevalent in the current generation than the previous one. ${ }^{1}$ This can be explained by the fact that our modern civilization comes into contact with a large number of materials, chemicals, and drugs. As a results, around $30 \%$ of the population has some kind of allergy nowadays. ${ }^{1}$ Symptoms may affect the upper airways, the skin, and the eyes. The most common factors that induce allergies are metals, foods, and drugs.

As the number of materials used in dentistry has increased considerably, the predisposition to allergies has grown as well. Dental materials, such as nickel, amalgam, cobalt, acrylates, and dental composites, can produce intra- or extra- 
oral symptoms of various severity. Four types of allergic reactions are known: types I, II, and III are mediated by antibodies (IgE, IgG), causing immediate allergic reactions, while type IV is mediated by cells and is known as delayed reaction. ${ }^{2}$ The dose that triggers an allergic reaction may vary from person to person due to previous sensitization to one or more compounds. Furthermore, cross-sensitivity, when sensitivity to a certain substance triggers an allergic reaction to another material with similar properties, may also be an important factor. All these must be taken into consideration when working with different materials in restorative dentistry. ${ }^{2}$ Concurrent sensitization, when two allergens are present at the same time and generate a parallel allergic reaction, is another important factor, very often generated by dental alloys.

Given the rising occurrence of hypersensitivity reactions, there is an increasing need to find out the exact causes and the relative incidence of allergies in our society. The aim of this study was to assess dentists' experience regarding the occurrence of allergies in their practice among patients and dental team members.

\section{MATERIALS AND METHODS}

The present study was based on a questionnaire consisting of 16 questions. Online and onsite versions of the questionnaire were delivered to active dentists from Mureș county.

The first questions referred to demographic data of the dentists, such as age, sex, specialty, and workplace. The next questions referred to the dentist's experience regarding allergies in the daily practice. We asked about the frequency of allergic reactions in the dental office, the age of allergic patients, data about the last patient that had an allergic reaction, the type of the allergic reaction, the material which caused the allergic reaction, the therapy used by the dentist, and whether the patient was referred to a specialist. The last two questions referred to the presence of allergic reactions among dentists themselves or any other member of the dental staff.

The questionnaires were filled out anonymously and voluntarily by the dentists. To assess the results, the answers were transferred into Microsoft Excel sheets, where descriptive statistics and chi square tests were applied for statistical analysis.

\section{RESULTS}

A total of 104 dentists completed the questionnaire, of which $66 \%$ were female and $34 \%$ male. Regarding their age, $66 \%$ were between $25-35$ years, $19 \%$ between $35-45$ years, $13 \%$ between $45-55$ years, and $2 \%$ were above 55 years. Only $13 \%$ of the respondents were working in a rural area, $87 \%$ were working in an urban area. Almost two-thirds of the respondents (64\%) were working for less than 10 years, $24 \%$ were having $10-20$ years of experience, while $12 \%$ were working for more than 20 years.

Almost half of the respondents (44\%) were general dentists, $18 \%$ orthodontists, $15 \%$ prosthodontists, $10 \%$ dental surgeons, $9 \%$ endodontists, and $4 \%$ periodontists.

The answers showed that $23 \%$ of the participants had a patient with an allergic reaction each year, $9 \%$ at every $2-3$ years, $48 \%$ very rarely, while $20 \%$ of the dentists had not yet met allergic reactions in the daily practice.

According to the answers, in $52 \%$ of cases the last patient with an allergic reaction was female, in $18 \%$ of cases it was male, and $30 \%$ of the respondents did not remember the sex of the last patient with an allergic reaction. Hypersensitivity was met by $74 \%$ of the dentists, predominantly in active adult patients between $20-60$ years of age. In $14 \%$ of the cases the patient was under 18 years, and in $12 \%$ the patient was above 60 years.

Dental allergies may produce immediate or delayed reactions. In our study, $68 \%$ of the respondents have met immediate reactions, with symptoms appearing during or immediately after the treatment, and $32 \%$ have met delayed reactions, which appeared after a couple of weeks or months following the treatment.

The causes of immediate and delayed reactions are presented in Figure 1 and Figure 2. In the case of immediate reactions, more than half of the symptoms were caused by drugs, local anesthetics, or disinfectants (Figure 1).

In the case of delayed reactions, most of them were caused by acrylates, followed by different metals (Figure 2 ). There were no statistically significant differences between different age categories regarding the cause of allergic reaction ( $p>0.05)$, although it was observed that in case of children the delayed reactions were caused mainly by metals from the orthodontic appliances. In patients above 60 years, the main causes of delayed reactions were acrylates from dentures and different metals from dental prostheses.

The most frequently met symptoms among patients with sensitivity were burning mouth syndrome, followed by cheilitis and stomatitis (Figure 3 ).

Regarding the above-mentioned symptoms, the majority of dentists (38\%) removed the prosthesis as the possible cause, $29 \%$ recommended a systemic antihistaminic treatment, $18 \%$ opted for local antihistamines, and $15 \%$ asked for the opinion of a dermatologist. To the question regarding testing their patients for allergies, $44 \%$ answered that 


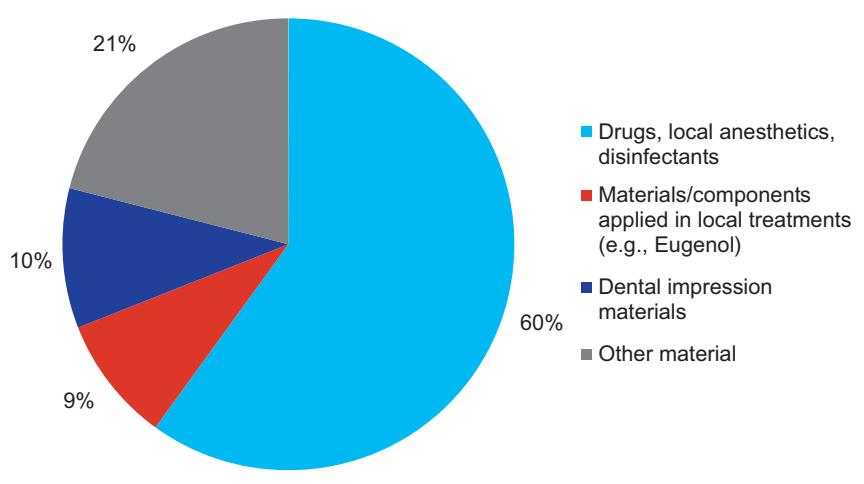

FIGURE 1. Causes of immediate allergic reactions

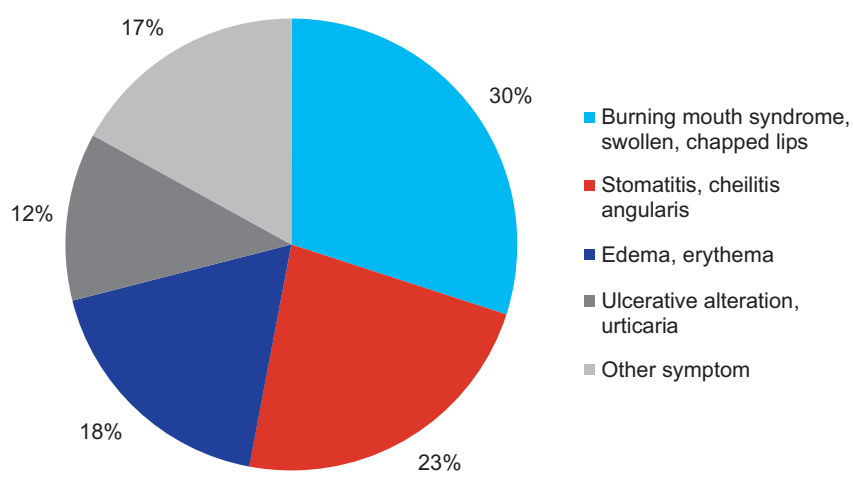

FIGURE 3. Symptoms met by the respondents

very rarely have they referred their patient to allergy tests, $41 \%$ had never recommended the consult of an allergy specialist, and only $15 \%$ of the respondents had sent their patient regularly to an allergologist. There were no statistically significant differences between dentists with less than 15 years or more than 15 years of experience $(p=0.23)$.

Possible allergic reactions affect not just the patients, but also members of the dental team, including dentists, dental assistants, and dental technicians. The last two questions of the questionnaire referred to this problem. Materials causing hypersensitivity in dental team members are shown in Figure 4. Latex allergy and contact dermatitis caused by different restorative materials were the most frequently encountered allergic reactions, and $51.42 \%$ of male dentists and $56.52 \%$ of female dentists have experienced some kind of allergic reaction themselves, without statistically significant differences between genders $(\mathrm{p}=0.62)$. The most common causes of allergic reactions were disinfectants in female members and latex in male members of the dental team.

Dentists reported a total number of 78 cases with symptoms, $69.23 \%$ of these being symptoms of immediate allergic reactions. No statistically significant associations were found between the treatment options chosen for

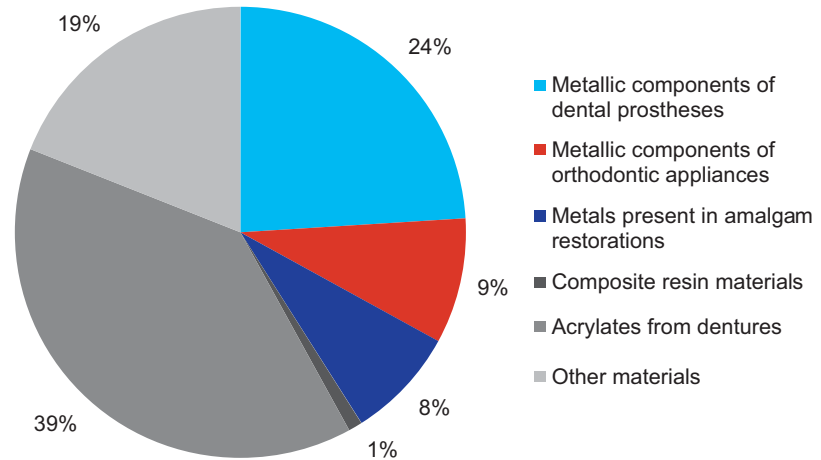

FIGURE 2. Causes of delayed allergic reactions

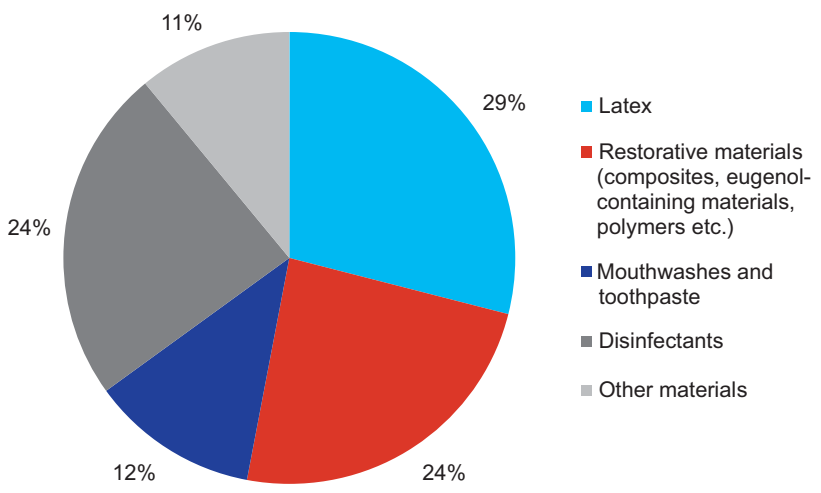

FIGURE 4. Materials causing allergic reactions in dental team members

immediate and delayed allergic reactions $(\mathrm{p}=0.87)$. The symptoms did not influence the treatment options chosen by the dentists. Additionally, some symptoms remain untreated, regardless of the type of allergic reaction.

In the case of latex allergy, we computed further comparisons between women and men. In our survey, 18 women and 7 men had latex allergy, but the difference was not significant statistically $(\mathrm{p}=0.75)$. Similar results were obtained regarding sensitivity to disinfectants, where 17 women and 5 men had an allergic reaction $(p=0.35)$. Finally, we conducted a comparative analysis between genders for all types of allergies. Although women presented more frequently allergic symptoms than men, the difference was not significant $(\mathrm{p}=0.3)$.

\section{DISCUSSIONS}

Almost every material our body comes into contact with may become an allergen. At least 6-12 days are needed for the development of hypersensitivity, or 24-48 hours if the allergy was present previously. Some of the materials used in dentistry may cause hypersensitivity reactions, the most known allergens being metals and different alloys, 
such as amalgam, palladium, nickel, cobalt etc., followed by acrylates from dentures. Serious hypersensitivity reactions may be caused by latex, which affects members of the dental staff especially, as the results of our questionnaire show. Several studies suggest that the prevalence of latex allergy among the general population is $4.3 \%$, while among healthcare workers is $9.7 \% .^{3}$ Latex may be one of the most common allergens among dental team members. ${ }^{4}$ Components of restorative materials, such as composites and dental adhesives, may also be a serious cause of hypersensitivity. Colophony, a ubiquitous contact sensitizer and a compound of impression materials and varnishes, also produces allergic reactions. ${ }^{5,6}$ Lidocaine, the most common local anesthetic in dentistry, is another important allergen that can produce severe symptoms, even anaphylactic shock. ${ }^{7,8}$ However, Peroni et al. stated that allergy to local anaesthetics is a rare condition in children, and a complete diagnostic procedure allows the correct identification of pediatric patients. ${ }^{9}$

The identification of a specific allergen may be difficult in certain cases, because these materials are present in complex compositions. The present study aimed to assess the main categories of materials causing allergic reactions in daily dental practice, without focusing on the specific components of the materials.

The scientific literature contains a large number of studies regarding dental allergies. A German study examined which gender is prone to sensitivity to toothpastes and found that mostly women are susceptible to these materials. ${ }^{10}$ The present study also showed that mouthwashes and toothpastes cause hypersensitivity more frequently in women than in men, but without a statistical significance.

Another study has shown that allergy to metals is very frequent, especially nickel allergy $(9-20 \%) .{ }^{11}$ In the present study, $24 \%$ of the cases were caused by different metals from orthodontic appliances and dental prostheses. Symptoms caused by metals were similar to those found in the aforementioned study.

An Indian questionnaire-based study examined different allergic reactions. ${ }^{12}$ There were 100 respondents, $60 \%$ of which were women. The main causes of allergic reactions were metals, in both patients and dentists. Acrylates and latex were the main causes of immediate allergic reactions. Local anesthetics produced immediate reactions in $0.5 \%$ of the cases. The main symptom was contact dermatitis, which was treated by antihistaminic drugs. The findings in our study are in accordance with these results.

The present study has shown that immediate allergic reactions are more frequent than delayed reactions caused by different dental materials. These reactions are usually triggered by drugs, local anesthetics, and disinfectants. Symptoms related to these reactions include burning sensation, swollen lips, and itching. Dentists choose antihistaminic drugs as a treatment in these cases. Delayed allergic reactions are mostly caused by acrylates and metals from dental prostheses. A Bulgarian questionnaire-based study found that one-fifth of complaints related to acrylates could be due to allergic reasons. ${ }^{13}$ In these cases, dentists choose to remove the prosthesis and offer restoration possibilities based on other materials.

It is important to note that anamnestic details reported by the patient may help in preventing allergic reactions in the dental office. Allergies to jewelry (rings, necklaces) made from different metals can help identify which dental alloys would be potential allergens. ${ }^{1}$ If a patient has never been in contact with a specific dental material, an allergy test, such as patch tests, skin prick tests, intradermal tests, and MELISA test for metals can be recommended. ${ }^{8,14}$

With the increasing prevalence of allergies among patients and the large number of materials used in dentistry, dental practitioners need to be aware of dental material components that are potential allergens.

\section{CONCLUSIONS}

Our results suggest that hypersensitivity to dental materials is present mostly among active adults, women being more susceptible. Immediate reactions are more commonly present than delayed reactions, and allergy affects both patients and dentists. Latex is the main allergen among specialists, while drugs, local anesthetics, disinfectants, acrylates, and metals are the main allergens in patients. The most common symptoms encountered by dentists include burning mouth syndrome and swollen lips.

\section{CONFLICT OF INTEREST}

Nothing to declare.

\section{REFERENCES}

1. Nékám K. Allergia - környezetünk csapdája. Budapest: Springmed, 2003

2. Schmalz G, Bindslev DA. Biocompatibility of dental materials. Berlin, Heidelberg: Springer Verlag, 2009.

3. Wu M, Mclntosh J, Liu J. Current prevalence rate of latex allergy: Why it remains a problem? J Occup Health. 2016;58:138-144.

4. Meena Sy, Radhika Ch, Vinod S. Allergic Reactions to Dental Materials. A Systematic Review. Journal of Clinical and Diagnostic Research. 2015;9:ZE04-ZE09.

5. Temesvári E. Fogászati kontakt allergének. Börgyógyászati és Venerológiai Szemle. 2009;80:53-61.

6. Sharma PR. Allergic contact stomatitis from colophony. Dent Update. 2006;33:440-442. 
7. Jiseon L, Ju-Young L, Hyun Jeong K, Kwang-Suk S. Dental anesthesia for patients with allergic reactions to lidocaine: two case reports. J Dent Anesth Pain Med. 2016:16:209-212.

8. Batinac T, Sotosek Tokmadzic V, Peharda V, Brajac I. Adverse reactions and alleged allergy to local anesthetics: Analysis of 331 patients. J Dermatol. 2013:40:522-527.

9. Peroni D, Pasini M, lurato C, Cappelli S, Giuca G, Giuca MR. Allergic manifestations to local anaesthetic agents for dental anaesthesia in children: a review and proposal of a new algorithm. Eur J Paediatr Dent. 2019;20:48-52

10. Van Baelen A, Kerre S, Goossens A. Allergic contact cheilitis and hand dermatitis caused by a toothpaste. Contact Dermatitis. 2016;74:187-189.

11. Wiltshire W, Noble J. Allergies to dental materials. Vital. 2007;4:39.

12. Abilasha R, Kadambari S. Awareness of Allergic reactions to Dental drugs and materials among Patients, Dentists and Dental personnel - A Cross sectional Study. J Pharm Sci \& Res. 2016;8:1050-1057.

13. Chonin A, Stoeva I. Clinical manifestations of intraoral contact hypersensitivity among dental patients with methacrylate. Journal of IMAB. 2016;22:1411-1413.

14. Vörös L, Altmayer A, Kemény L, Bata Zs. A fogászati kontaktallergénekkel szembeni érzékenység vizsgálata. Börgyógyászati és Venerológiai Szem/e. 2013:89:132-136. 